\title{
COMPETENCIAS GERENCIAIS: A PERCEPÇÃO DOS GESTORES DE UMA UNIVERSIDADE PÚBLICA
}

\section{MANAGERIAL COMPETENCIES: THE PERCEPTION OF MANAGERS OF A PUBLIC IES}

\author{
Andrea Kaliany da Costa Lima ${ }^{1}$ \\ Lydia Maria Pinto Brito ${ }^{2}$
}

\section{RESUMO}

A exigência de competências nas organizações começa a ficar evidente. A cobrança por resultados não é diferente nas Instituições de Ensino Superior (IES). Sob à luz de marcos teóricos (LE BOTERF, 2003; RUAS, 2005) este trabalho é resultado de uma investigação com gestores da Universidade do Estado do Rio Grande do Norte (UERN). Propôs-se analisar a percepção deles sobre as competências ideais necessárias ao exercício da gestão. A pesquisa é de natureza quantitativo-qualitativa, realizada por meio da aplicação de questionários, com questões abertas e fechadas. Desenvolveu-se uma pesquisa descritiva e estudo de campo, tendo como participantes 40 gestores da IES, em diferentes cargos. Os resultados revelaram que esses gestores sinalizam comprometimento com a função que exercem e com a IES, defendem a importância do planejamento e do agir com ética nas ações que desenvolvem. A Instituição parece necessitar de um processo de sensibilização a fim de sistematizar programas e acompanhamentos que contribuam para o desenvolvimento das competências gerenciais em seus gestores como forma de melhor subsidiá-los nas tomadas de decisões. Portanto, os objetivos propostos foram atingidos, uma vez que se buscou analisar esta percepção. Este estudo oferece abertura para novas pesquisas a outros atores do processo.

PALAVRAS-CHAVE: Competências Gerenciais - Gestores - Universidade.

\footnotetext{
ABSTRACT

The requirement of competence in organizations begins to become clear. The accountability for results is not different in Higher Education Institutions (HEIs). Under the light of theoretical frameworks (LE BOTERF, 2003; RUAS, 2005) this work is the result of an Revista LABOR 
investigation with the managers of the State University of Rio Grande do Norte (UERN). Proposed to analyze their perception of the ideal skills required to perform management. The research is a quantitative-qualitative, conducted through questionnaires with open and closed questions. Developed a descriptive and field study, and the participants were 40 managers of HEIs in different positions. The results revealed that these managers indicate commitment to the role they play and the IES, advocate the importance of planning and acting ethically in the activities they carry out. The institution seems to require a process of awareness in order to systematize and monitoring programs that contribute to the development of managerial skills among managers as a way to better subsidize them in decision making. Therefore, the objectives have been achieved, as it seeks to analyze this perception. This study provides the opening for further research to other actors in the process.

KEYWORDS: Managerial Competence - Managers - University.

\section{INTRODUÇÃO}

As organizações enfrentam, cotidianamente, um processo de competição. Desta forma, elas devem oferecer um diferencial a fim de sobressair-se neste mercado de múltiplas opções. Destarte, esta competição exige um processo de reestruturação. Percebe-se que a necessidade de mudanças deixou de ser um evento pontual e transformou-se em um modo (obrigatório) de conduzir os negócios. Com isso, um fator de sucesso neste tempo de profundas e difíceis transformações é saber gerir, com sabedoria, o fluxo contínuo de informações e novidades que todos os dias aparecem e, também, gerenciar com discernimento os complexos movimentos de mudanças para fazer frente aos desafios.

Para Almeida (2000), os dirigentes da universidade brasileira ainda não praticam o que ensinam os cursos de administração. O autor destaca que as circunstâncias em que os gestores são conduzidos aos cargos de direção, muitas vezes, os levam a tomarem decisões que tragam prestígio e que, simultaneamente, evitem custos políticos ou até perda de seus cargos. A maioria dos ocupantes de cargos de direção nas universidades públicas é professor, os quais não se sentem gerentes e tampouco agem como tal, pois esses profissionais têm a docência como carreira e não a função gerencial.

A exemplo de qualquer organização e de outras IES espalhadas pelo país, a 
Universidade do Estado do Rio Grande do Norte (UERN) precisa conhecer os seus gestores e as competências por eles apresentadas. Assim a questão central do presente estudo é: Qual a percepção dos gestores que atuam na Universidade do Estado do Rio Grande do Norte sobre as competências ideais necessárias ao exercício da gestão? Seu objetivo geral é analisar a percepção dos gestores que atuam na Universidade do Estado do Rio Grande do Norte sobre as competências ideais necessárias ao exercício da gestão. Tem como objetivos específicos: verificar se os gestores percebem a gestão de competências como uma política da instituição; identificar os conhecimentos necessários para que os gestores obtenham um bom desempenho; mapear as habilidades que a instituição exige para o desenvolvimento das funções gerenciais; identificar como ocorre o processo de aprendizagem para o exercício da gestão; e verificar as atitudes essenciais para os gestores executarem suas atividades. Com relação a metodologia trata-se de um estudo de campo descritivo, com abordagem quantitativo-qualitativa.

Portanto, pode-se destacar que este estudo é relevante em razão do crescimento da instituição pesquisada com a oferta de novos cursos, expansão pelo interior do estado do $\mathrm{RN}$ e competitividade do mercado com oferta de cursos por outras IES na cidade. Outro fato relevante é que ainda não foi desenvolvido nenhum estudo dessa natureza na organização pesquisada. Um estudo dessa ordem pode oferecer uma grande contribuição acadêmica e, também, um direcionamento das ações desta instituição que caracterizam o ambiente contemporâneo. O presente artigo é composto, além desta Introdução de 2.Referencial Teórico, 3. Metodologia, 4. Discussão dos resultados e Considerações Finais.

\section{REFERENCIAL TEÓRICO}

O conceito de competência começou a adquirir novos significados e a importância que tem hoje, a partir de estudos feitos por David C. McClelland, no início da década de 70. (ZARIFIAN, 2008).

A valorização e a popularização do novo conceito de competência tendem a determinar uma importância ao fator escolaridade, incluindo os cursos como MBA, pósgraduação ou mestrado, pelo menos para fins de seleção e promoção de pessoal. Contudo, as escolas que promovem esses cursos devem incluir em seus programas formas mais efetivas para desenvolver competências, visto que as competências não se restringem apenas ao 
aumento do grau de conhecimento, e sim à aplicação deste conhecimento (RESENDE, 2000).

Segundo Zarifian (2008, p. 17):

Durante mais de dez anos, a questão da competência permaneceu em campo restrito às experiências desenvolvidas por empresas líderes e às discussões de especialistas. Para além desse círculo relativamente reduzido, elementos de uma nova lógica podiam ser adotados, e efetivamente o eram (como a prática das entrevistas individuais para os assalariados da base da estrutura organizacional), mas isto ocorria de maneira parcial e fragmentada, que não questionava os mecanismos do campo, da gestão, dos recursos humanos ou das relações profissionais.

As competências para Flannery, Hofrichter e Platten (1997, p. 107) "são habilidades, conhecimentos, capacidades, características comportamentais e outros atributos que na combinação correta e dentro do conjunto certo de circunstâncias, predizem o desempenho superior”. Nesta mesma linha de pensamento, Le Boterf (2003), também, trata o referido conceito e afirma que a competência se desenvolve por meio da atuação do indivíduo, o qual atua e desenvolve os seus processos de competência, utilizando-se de seus conhecimentos e ações, realizados no contexto profissional. O desenvolvimento das competências dá-se por meio de um modelo combinatório que utiliza elementos chamados de recursos de cunho individual, seguidos de elementos pertencentes ao meio no qual ele está inserido e, finalmente, agrega elementos externos capazes de formar a competência na íntegra. Essa integração gera a competência coletiva, responsável por um conjunto de situações que identificam a empresa e formam a sua identidade em termos de competências.

Para Zarifian (2008, p. 56), “a competência não é uma negação da qualificação. Pelo contrário, nas condições de uma produção moderna, representa o pleno reconhecimento do valor da qualificação. O trabalho reverte ao trabalhador". Ou seja, a responsabilidade de se ter qualificação estava relacionada ao trabalho. Com isso, as organizações é que precisavam investir nos funcionários para obterem uma maior produção. No entanto, a partir do momento em que o trabalhador tomou para si a responsabilidade de ter uma qualificação para manter-se em seu trabalho, a empresa, de certa forma, transferiu essa obrigação para os funcionários.

Resende (2000, p. 29) defende que o termo competência não é novo. De acordo com ele "a competência - assim como qualidade e melhoria contínua - é uma ideia antiga, reconceituada e revalorizada no presente, como resultante de movimentos econômicos e culturais, conforme demonstrado anteriormente". A competência é vista, também, como uma faculdade de mobilizar redes de atores em torno das mesmas situações e de fazer com que os atores compartilhem as implicações de suas ações. Ou seja, ela é capaz de fazê-los assumir Revista LABOR $\quad \mathbf{n}^{\circ} 15, \mathrm{v} .1,2016$ 
áreas de co-responsabilidade. "A competência é 'o tomar iniciativa' e o 'assumir responsabilidade' do indivíduo diante de situações profissionais com as quais se depara" (ZARIFIAN, 2008, p. 68). Resende (2000) diz que o significado de competência que tem adquirido força, nos últimos tempos, está relacionado com uma condição diferenciada de qualificação e de capacitação das pessoas para executar o seu trabalho e de desempenhar as suas atividades. Inicialmente o conceito de competência era mais aplicado às pessoas, mas em um segundo momento passou a ser usado, também, como um requisito de bom desempenho de equipes, unidades e da empresa.

Todavia, o termo competência, que acompanha o profissionalismo, só ganhou importância no decorrer dos anos 80 . Na década de 70, era a noção de "qualificação" que dominava. "[...] As noções de competência e de profissionalismo parecem mais adaptadas à gestão da mobilidade profissional do que aquela de qualificação, mais apropriada a um contexto de estabilidade das profissões" (LE BOTERF, 2003, p. 16).

Fischer et al. (apud RUAS, 2005) defende que o conceito de competência pode ser utilizado como referência para a construção de instrumentos de gestão e, ainda, como forma de compreender a gestão de pessoas na empresa moderna. A competência é uma disposição, e não um gesto elementar. Ser competente é saber coordenar e, até mesmo, saber improvisar coordenações (LE BOTERF, 2003).

Frente à grande variedade de significados atribuídos, pelas várias escolas de estudos, americanas, espanhola, francesas e latino-americanas, ao termo competência, percebe-se que todas apontam para um ponto de convergência, defendido por Dutra (2002, p. 22), o qual afirma que: "podemos falar em competência apenas quando há competência em ação, traduzida em saber ser e saber mobilizar conhecimentos em diferentes contextos”. Já Le Boterf (2003) e Zarifian (2008) fazem uso do termo competência como sendo as realizações da pessoa dentro de um determinado contexto, ou seja, aquilo que é produzido ou realizado por ela no trabalho.

Os assuntos voltados para a competência, no Brasil, são tratados por alguns autores como, por exemplo, Ruas (2005), Antonello (2005), Boff (2005), Bitencourt (2001) e Fleury e Oliveira Júnior (2001), como resultados de pesquisas empíricas. Nessa perspectiva, entendese que a competência é associada à Gestão de Recursos Humanos e suas práticas. Resende (2000) destaca que o início do movimento de valorização da competência começou nos EUA - de onde surgem quase todos os modelos de organização e gestão administrativa. Nesse sentido, somente no final da década de 80 este movimento chegou ao Brasil. E no final da 
década de 90 ele começou a tomar corpo. Para Gramigna (2007) este modelo que vem se delineando é um dos mais adequados aos novos tempos: a gestão por competências. Já difundido nos Estados Unidos e em franco crescimento na Europa, o movimento chega de forma ainda tímida no Brasil, tendo nas multinacionais e nas novas empresas o seu berço. Para a autora (2007), enquanto no Brasil começavam a buscar novas formas de tornar as empresas mais competitivas, nos Estados Unidos e na Europa a gestão por competências caminhava a passos largos, apresentava resultados significativos e já disponibilizava literatura razoável a respeito.

Para Fleury e Oliveira Júnior (2001), no contexto brasileiro, a construção do modelo de Competência, se tem como espinha dorsal a estrutura de cargos, cuja referência está centrada no modelo taylorista de organização do trabalho, sendo introduzido no Brasil na década de 30. Nos anos 80 existia uma preocupação com a qualidade e a produtividade, emergindo, assim, em um espaço para se pensar em novas formas de organização e gestão do trabalho. Segundo os autores (2001), se buscava inspiração na experiência dos grupos ditos semi-autônomos europeus e nas práticas bem-sucedidas da conhecida indústria automobilística japonesa.

Ruas (2005) defende que a crescente utilização da noção de "competência" no ambiente empresarial brasileiro tem renovado o interesse sobre o conceito. Longe, no entanto, de se construir um universo homogêneo. $O$ que se percebe é que a noção de competência apresenta muitas indefinições, o que, certamente, dificulta a sua utilização adequada por parte das empresas. Para Ramos (2001) a construção teórico-metodológica oficial de um conceito de competência no Brasil, pelo menos no âmbito profissional, mantêm-se determinada por uma influência exógena de caráter funcionalista. Essa abordagem parece mais apropriada à gestão taylorista-fordista do que a qualquer perspectiva mais qualificante.

Portanto, as empresas brasileiras ainda têm de evoluir muito no quesito competência. Para que as organizações no Brasil absorvam este conceito de gestão de competência é preciso, antes de qualquer coisa, que ocorra uma verdadeira transformação organizacional e o envolvimento das pessoas, uma vez que não se podem incorporar meros conceitos formados e querer obter resultados imediatos, se as pessoas envolvidas não incorporarem o processo de mudança. 


\section{METODOLOGIA}

A pesquisa é considerada, quanto ao seu objetivo, como descritiva (GIL, 2007; BOENTE; BRAGA, 2004). Quanto aos procedimentos de investigação é classificada como estudo de campo. O tipo de pesquisa utilizada é de natureza quantitativo-qualitativa, com intuito de captar informações relevantes para o conhecimento das competências apresentadas pelos gestores da instituição pesquisada.

O universo da pesquisa realizada com os gestores da Universidade do Estado do Rio Grande do Norte (UERN) é constituído por todos que exercem atividades gerenciais na cidade de Mossoró-RN, no nível estratégico e tático, conforme apresentado na tabela 1.

Tabela 1 - Quantitativo de Gestores da UERN - Campus Mossoró

\begin{tabular}{l|c}
\hline \multicolumn{1}{c}{ Categoria } & Quantidade \\
\hline Alta Direção & 06 \\
\hline Diretores & 10 \\
\hline Chefes de Departamento & 24 \\
\hline Total de gestores da UERN - Campus Mossoró & 40 \\
\hline
\end{tabular}

Fonte: PROHAE - Pró-Reitoria de Recursos Humanos e Assuntos Estudantis.

Contudo, optou-se por não delimitar uma amostra e trabalhar com todo o universo da pesquisa. Assim, a pesquisa é censitária, com distribuição de questionários a todos os gestores que atuam na UERN, no Câmpus de Mossoró.

Quanto ao resultado da pesquisa, obtiveram-se as respostas de todos os gestores, em um universo de 40, o que dá uma taxa de retorno de 100\%. Dessa forma, pode-se ter a real percepção dos gestores da IES pesquisada quanto às competências.

Este estudo foi desenvolvido por etapas. A primeira foi a definição do questionário, bem como a definição dos grupos de gestores (alta administração, diretores de faculdades e chefes de departamento). Na segunda etapa realizou-se a aplicação do questionário. Entretanto, antes de ser entregue ao grupo de gestores da UERN, o mesmo foi avaliado por um grupo de 10 funcionários da própria Instituição, com o intuito de observar à sua clareza e compreensão. A partir das observações feitas pelos respondentes realizaram-se pequenas alterações. Assim, o instrumento foi validado em pré-teste. Em seguida, na terceira etapa, executou-se a aplicação dos questionários com os gestores. Os questionários foram distribuídos pessoalmente pelas pesquisadoras, e o seu retorno era agendado de acordo com a disponibilidade do gestor em responder. 
O levantamento dos dados foi viabilizado por meio do questionário construído pelas pesquisadoras, e utilizou como referência o modelo de Braga e Brito (2009), bem como os objetivos propostos para este estudo. O questionário aplicado constou de três partes: a primeira buscou identificar o perfil dos gestores; a segunda identificou o perfil de competências gerenciais dos gestores, avaliando o indicador cognitivo (conhecimentos) e o indicador comportamental (habilidades e atitudes); e a terceira foi classificada como desenvolvimento profissional, onde os gestores teriam que responder a cinco questões abertas. Essas questões, de acordo com Lima (2004), proporcionam ao respondente desenvolver-se de forma livre.

Neste estudo foram consideradas as seguintes variáveis: Gestão de competências (conhecimentos, habilidades e atitudes); processos de aprendizagem e política institucional.

Os dados obtidos foram analisados por meio de estatística descritiva e análise de conteúdo. Utilizou-se da análise de conteúdo para categorizar as respostas dadas pelos gestores na terceira parte do questionário. Sendo assim, foi mantida a originalidade das falas dos pesquisados. Os questionários foram codificados para que a identidade do gestor fosse preservada. Essa codificação é representada por uma letra maiúscula, que representa o cargo em que o gestor atua, e um número, conforme demonstra o quadro 1.

Quadro 1 - Codificação Do Grupo De Gestores Pesquisados.

\begin{tabular}{|c|c|c|c|c|c|c|c|c|c|c|}
\hline Categoria & \multicolumn{10}{|c|}{ Quantificação } \\
\hline Alta Direção & A01 & $\mathrm{A} 02$ & $\mathrm{~A} 03$ & A04 & $\mathrm{A} 05$ & A06 & - & - & - & - \\
\hline $\begin{array}{c}\text { Diretores de } \\
\text { Faculdades }\end{array}$ & D01 & D02 & D03 & D04 & D05 & D06 & D07 & D08 & D09 & D10 \\
\hline \multirow{3}{*}{$\begin{array}{c}\text { Chefes de } \\
\text { departamentos }\end{array}$} & $\mathrm{C} 01$ & $\mathrm{C} 02$ & $\mathrm{C03}$ & $\mathrm{C} 04$ & $\mathrm{C} 05$ & C06 & $\mathrm{C} 07$ & $\mathrm{C} 08$ & $\mathrm{C} 09$ & $\mathrm{C} 10$ \\
\hline & $\mathrm{C} 11$ & $\mathrm{C} 12$ & $\mathrm{C} 13$ & $\mathrm{C} 14$ & $\mathrm{C} 15$ & $\mathrm{C} 16$ & $\mathrm{C} 17$ & $\mathrm{C} 18$ & C19 & $\mathrm{C} 20$ \\
\hline & $\mathrm{C} 21$ & $\mathrm{C} 22$ & $\mathrm{C} 23$ & C24 & - & - & - & - & - & - \\
\hline
\end{tabular}

Fonte: Elaborado Pelas Pesquisadoras.

\section{ANÁLISE E DISCUSSÃO DOS DADOS}

Neste tópico serão apresentadas as características da amostra, a análise efetuada sobre os dados e uma breve discussão dos resultados.

\subsection{Ambiente e Sujeitos da Pesquisa}


A IES foi fundada em 18 de agosto de 1943. A Universidade do Estado do Rio Grande do Norte (UERN) é a única IES pública da esfera estadual no Rio Grande do Norte (RN). Esta condição merece destaque no cenário educacional local, sobretudo quando se leva em conta que o Câmpus central está localizado em Mossoró, uma cidade do interior do Estado. A Universidade conta com 5 Campi Avançados e 11 Núcleos Avançados de Educação Superior, que atende o estado do Rio Grande do Norte com a oferta de 24 cursos. A referida Instituição, por meio do seu Plano de Desenvolvimento Institucional (PDI), tem incentivado os seus professores e técnicos a se capacitarem, liberando para cursarem mestrado e doutorado com bolsa de produtividade, e incentivando nos cursos de graduação à existência de Grupos de Pesquisas (GPs).

Inicialmente, buscou-se identificar o perfil dos gestores da UERN. Percebeu-se que quanto ao gênero, $65 \%$ dos que exercem cargo de direção são do sexo masculino e apenas $35 \%$ do feminino. Assim, verifica-se uma organização liderada em sua maioria por homens. A faixa etária revela que $45 \%$ dos gestores têm idade acima de 50 anos, 20\% entre 45 a 49 anos, $15 \%$ entre 40 a 44 anos, $15 \%$ estão entre 35 a 39 anos e apenas 5\% entre 30 a 34 anos. Nesse sentido, observando as categorias de gestores, na alta administração se concentram gestores com uma idade acima de 50 anos. Já nas chefias de departamento, os gestores estão distribuídos entre 30 e mais de 50 anos.

Um dos fatos interessantes, é que a Instituição em estudo não apresenta nenhum gestor na faixa etária de 25 a 29 anos; acredita-se que este fato se dá pelas exigências que se têm para concorrer aos cargos de gestores. No caso da chefia de departamento, o professor interessado em ser chefe, segundo o Estatuto da UERN, no art. $24-\S 3^{\circ}-$ O chefe e o subchefe de departamento serão eleitos entre os professores, com o mínimo de dois anos de efetivo exercício no departamento (grifo nosso), por meio de eleição, com sufrágio direto e secreto, pela plenária do departamento. Estes serão nomeados pelo reitor e empossados pela plenária do departamento. Acredita-se, com isso, que este fato justifica não existir chefes nesta faixa etária.

Quanto ao tempo de serviço na Instituição, verificou-se que $45 \%$ dos gestores apresentam mais de 20 anos, 30\% estão entre 11 a 20 anos, $15 \%$ entre 5 a 10 anos, e apenas $10 \%$ apresenta menos de 5 anos na IES. Estes dados mostram que os gestores têm uma vivência na organização e um tempo de serviço prestado que lhes confere experiência. Ao observar a informação nos grupos, os chefes de departamento apresentam gestores com um menor tempo de serviço na Instituição, e os diretores de faculdades apresentam maior tempo 
de serviço na universidade, o que mostra uma vivência maior às suas rotinas. Esta informação pode ser positiva, quando se trata da vivência na IES, e negativa, caso estes gestores apresentem certa acomodação e resistência às mudanças.

Em relação à formação acadêmica dos gestores, observou-se que $2 \%$ fizeram pósdoutorado, $38 \%$ são doutores, $25 \%$ mestres, $30 \%$ especialistas e 5\% graduados. Todos são docentes, ou seja, além das atividades de sala de aula, estão dedicados a cargos de gestão, confirmando o que a UERN defende em seu PDI, a capacitação de seus docentes. A capacitação merece destaque, uma vez que o Ministério da Educação (MEC) avalia os cursos, e este item é critério de qualidade. A UERN incentiva com bolsa de produtividade própria para os professores que cursam mestrado e doutorado no Brasil ou em outro país.

Diante disso, percebe-se que na alta administração 50\% dos gestores são doutores, nas direções de faculdades apresenta uma maioria de doutores e nas chefias de departamento uma presença igual de $33 \%$ mestres e doutores. Ao cruzar os dados observou-se que nenhum gestor com menos de cinco anos na Instituição é graduado ou especialista, comprovando mais uma vez o esforço em capacitar seus profissionais e um esforço dos gestores em buscar esta formação. Isso se deve também, aos últimos concursos realizados na Instituição que exigia uma titulação mínima de especialistas, mestres ou doutores.

Quanto ao regime de trabalho dos gestores verificou-se que $70 \%$ têm Dedicação Exclusiva (DE) e 30\% trabalham em regime de 40 horas semanais. Esta informação mostra que os gestores estão priorizando a universidade ao optarem por terem DE. Estratificando a informação nas categorias, verifica-se que todos da alta administração têm DE.

Quanto ao tempo que exercem atividade como gestor nesta função, observou-se que $50 \%$ apresenta menos de 2 anos na função, $40 \%$ estão entre 2 a 5 anos e $10 \%$ estão entre 6 a 10 anos. Essa realidade sinaliza que estes gestores já desenvolveram uma experiência considerável na função exercida e os professores estão querendo desenvolver papéis gerenciais na universidade, visto que a maioria deles está no cargo a menos de dois anos.

A UERN em sua estrutura organizacional está dando oportunidades aos gestores de desenvolverem papéis gerenciais ao apresentar um índice de $67 \%$ de chefes de departamento que estão na função a menos de 2 anos. Geralmente, o primeiro passo gerencial de um gestor na UERN é como chefe de departamento de curso. Esta informação é confirmada quando perguntado sobre as experiências gerenciais anteriores e se já haviam exercido cargo anteriormente na UERN. Nesse caso, $45 \%$ dos gestores disseram ter trabalhado em outros cargos gerenciais, como chefe de departamentos e assessorias, e 55\% disseram não ter atuado 
anteriormente em nenhum outro cargo. $\mathrm{O}$ cargo de gestor foi a sua primeira experiência na gestão, o que sinaliza que os cargos de gestão nesta IES estão sendo renovados e dando a oportunidade as pessoas de desenvolverem o seu espírito de liderança e a sua capacidade administrativa para gerir.

Observou-se que 67\% dos gestores que atuam nas chefias de departamentos nunca tinham exercido cargos anteriormente. Quanto os gestores da alta administração, 33\% nunca tinham exercido cargo de gestor. Nesse sentido, é importante destacar que para o cargo de chefe de departamento a escolha se dá em forma de eleição, ao contrário dos gestores da alta administração que são indicados/nomeados pelo reitor.

A esse respeito, importa destacar que autores como Le Boterf (2003), Sveiby (1998), Brandão e Guimarães (2001) e Ruas (2003) incluem em seus modelos de competência a experiência dos profissionais. Referem à importância de saber tirar lições da experiência, fazendo de sua prática profissional uma oportunidade de criação de saber. Para Medef (1998 apud ZARIFIAN, 2008, p. 66), "A competência profissional é uma combinação de conhecimentos, de saber-fazer, de experiências e comportamentos que se exerce em um contexto preciso". Assim sendo, Zarifian (2008) defende que a competência só se manifesta na atividade prática. Dessa forma, a atividade exercida pelos gestores é que permitirá uma avaliação das competências utilizadas.

A escolha dos dirigentes na UERN ocorre em processo de eleição, mas o reitor é nomeado pelo governador do estado. Os gestores da UERN, quando questionados sobre a forma de escolha dos dirigentes para atuarem nos cargos, $85 \%$ afirmaram que foram escolhidos em processo de eleição e $15 \%$ afirmaram que foram indicados para atuarem no cargo. Segundo o regimento da UERN, o processo de preenchimento de cargos ocorre por meio de processo eleitoral na forma definida no art. 14, do Estatuto da UERN, e em normas complementares baixadas pelo Conselho Universitário. Verificou-se que $100 \%$ dos diretores afirmaram que foram escolhidos em processos de eleição. Já na chefia de departamento, embora sua forma de escolha seja eleição, de acordo com estatuto da UERN, 8\% dos gestores afirmaram que estão no cargo por indicação, isto só é possível acontecer enquanto não existe o processo de eleição e o reitor indica alguém pró-tempore para o cargo. Na alta administração somente o reitor e vice-reitor são escolhidos em processo de eleição. Com isso, os cargos de pró-reitores são escolhidos por indicação do reitor. 


\subsection{Indicador Cognitivo - Conhecimentos}

Quanto a percepção dos gestores sobre competências gerenciais obteve-se os resultados a seguir. Inicialmente, foi solicitado que cada gestor escolhesse cinco variáveis que consideravam mais importantes para um gestor que atua na UERN. O primeiro indicador avaliado foi o indicador cognitivo, relacionado ao conhecimento. Este indicador, na visão de Braga e Brito (2009), refere-se ao saber teórico, conceitual, fundamental para orientar uma boa prática.

$\mathrm{Na}$ visão dos gestores, quanto aos conhecimentos, em primeiro lugar $90 \%$ consideram que a variável mais importante para um gestor possuir é conhecer o planejamento estratégico e operacional. Esta variável envolve o conhecimento de modelos e processos de planejamento, partindo desde o diagnóstico, definição de prioridades até o monitoramento/avaliação, a fim de orientar a adequada construção de planos de ação para a organização (Gráfico 1).

Gráfico 1 - Resultado Indicador Cognitivo (Conhecimento) - Frequência (\%).



Fonte: Pesquisa das autoras.

Este resultado confirma o que ressalta Campos (2007), ou seja, o planejamento é uma ferramenta administrativa, a qual pode garantir a sobrevivência de uma organização. No caso das universidades, o planejamento passa a ser cobrado como requisito legal. Ainda para a referida autora (2007), a cultura do planejamento é quase inexistente na universidade pública, 
que começa a entrar em uma fase, com novas exigências do governo federal, na qual estes conhecimentos e ações passam a ser necessários para qualquer dirigente.

A segunda variável escolhida pelos gestores, com $78 \%$, foi a gestão de pessoas, visto que se refere aos conhecimentos sobre administração de recursos humanos (principais sistemas de pessoal, como: planejamento de RH, seleção/suprimento, treinamento e avaliação de desempenho). Segundo os gestores, é importante conhecer as pessoas que trabalham na organização e proporcionar o desenvolvimento delas.

Já a terceira variável, com $72 \%$ das escolhas, foi a psicologia organizacional, uma vez que os gestores acreditam que é importante conhecer sobre o comportamento das pessoas dentro de uma organização (comunicação interpessoal, administração de conflitos, negociação, motivação e formação de equipes).

Nessa perspectiva, a visão de Campos (2007) assinala que os gestores devem conhecer também a estrutura organizacional e entender a complexidade da administração de um Câmpus universitário. Para Ruas (2003), este tipo de conhecimento está relacionado ao ambiente em que está inserido o profissional, e está ligado ao conhecimento de normas, regimentos e estatutos da Instituição.

Ao avaliar as informações apresentadas no gráfico 2, observa-se algumas divergências nas escolhas dos gestores se comparadas ao gráfico 1. No gráfico 2, por exemplo, $100 \%$ dos gestores da alta administração escolheram a gestão de pessoas como o conhecimento mais importante. Já os diretores e chefes de departamento mostraram uma preocupação maior com o planejamento estratégico e operacional, com $90 \%$ e $92 \%$ das escolhas, respectivamente.

Gráfico 2 - Indicador Cognitivo (Conhecimento) - Comparativo Por Categoria - Frequiência (\%). 


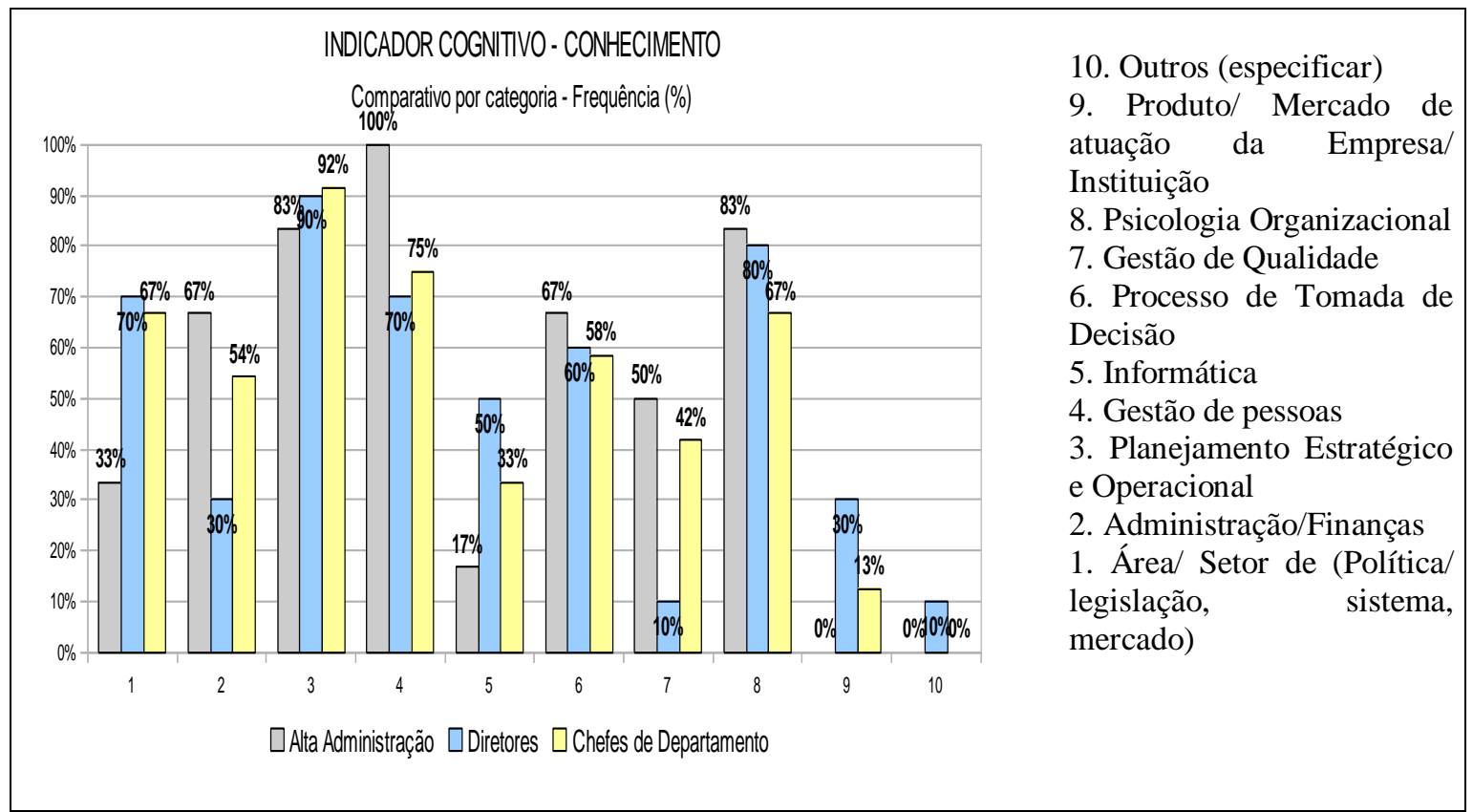

Fonte: Pesquisa das autoras.

Os resultados chamam a atenção também, para o indicador 9, Produto/Mercado de atuação da empresa/Instituição, uma vez que entre os membros da alta administração não recebeu nenhuma indicações entre as cinco variáveis mais importante, tendo sido o indicador que recebeu menor índice das outras categorias. Esta informação sinaliza que a Instituição não está tão preocupada com a sua atuação no mercado. Acredita-se que este fato ocorra porque a mesma é de natureza pública.

Contudo, apesar desta não ser a única IES pública na cidade, Mossoró dispõe de uma IES federal, a Universidade Federal Rural do Semi-árido (UFERSA). O município é considerado como uma cidade pólo, por ter o privilégio geográfico de se encontrar entre duas capitais. Com este aspecto, os municípios vizinhos buscam o comércio, a educação e a saúde na cidade. Este fato tem crescido muito o interesse de outras IES privadas em se instalarem na cidade.

\subsection{Indicador Comportamental - Habilidades}

O indicador comportamental (habilidades) também foi avaliado pelos gestores. No gráfico 3 observam-se as habilidades que os gestores consideram mais importantes possuir, ou 
seja, o saber fazer.

Gráfico 3 - Resultado indicador comportamental (habilidades) - frequência (\%).

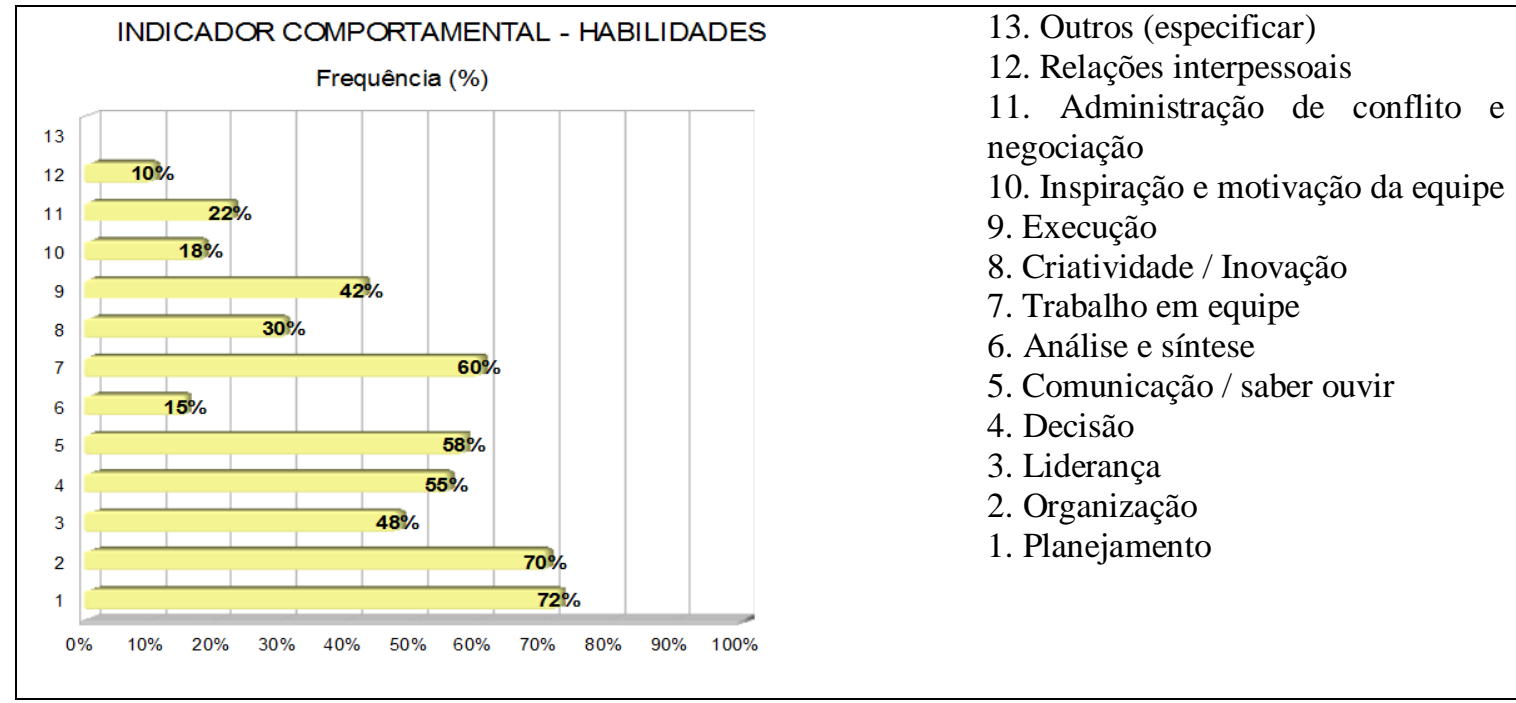

Fonte: Pesquisa das autoras.

O planejamento foi eleito pelos gestores a habilidade mais importante para um gestor possuir (72\%). Esta informação confirma a maior indicação na variável planejamento estratégico e operacional, no indicador cognitivo (conhecimento), o qual recebeu maior pontuação pelos gestores. Com isso, os gestores acreditam que esta capacidade de planejar, definir e compartilhar metas estratégias e táticas referentes ao processo administrativo é inerente ao cargo.

Com $70 \%$ das escolhas, em segundo lugar, classificado pelos gestores, ficou a organização. Refere-se à capacidade de gerenciar o processo administrativo, bem como de definir os diversos papéis dos membros da equipe, incluindo a distribuição de atividades, tarefas e responsabilidades. Sendo assim, a visão de organização como função administrativa envolve a noção de organização como uma parte do processo administrativo. Nesse sentido, é o agrupamento de atividades necessárias, a fim de atingir os objetivos da empresa.

A terceira variável escolhida como mais importante, com $60 \%$ das escolhas, foi o trabalho em equipe. Refere-se à habilidade pessoal que consiste na capacidade de entrosar-se facilmente com os demais membros da equipe e de converter-se em fator de integração do time como um todo, com ênfase na excelência das relações interpessoais. 
Gráfico 4 - indicador comportamental (habilidades) - Comparativo por categoria - frequência (\%).

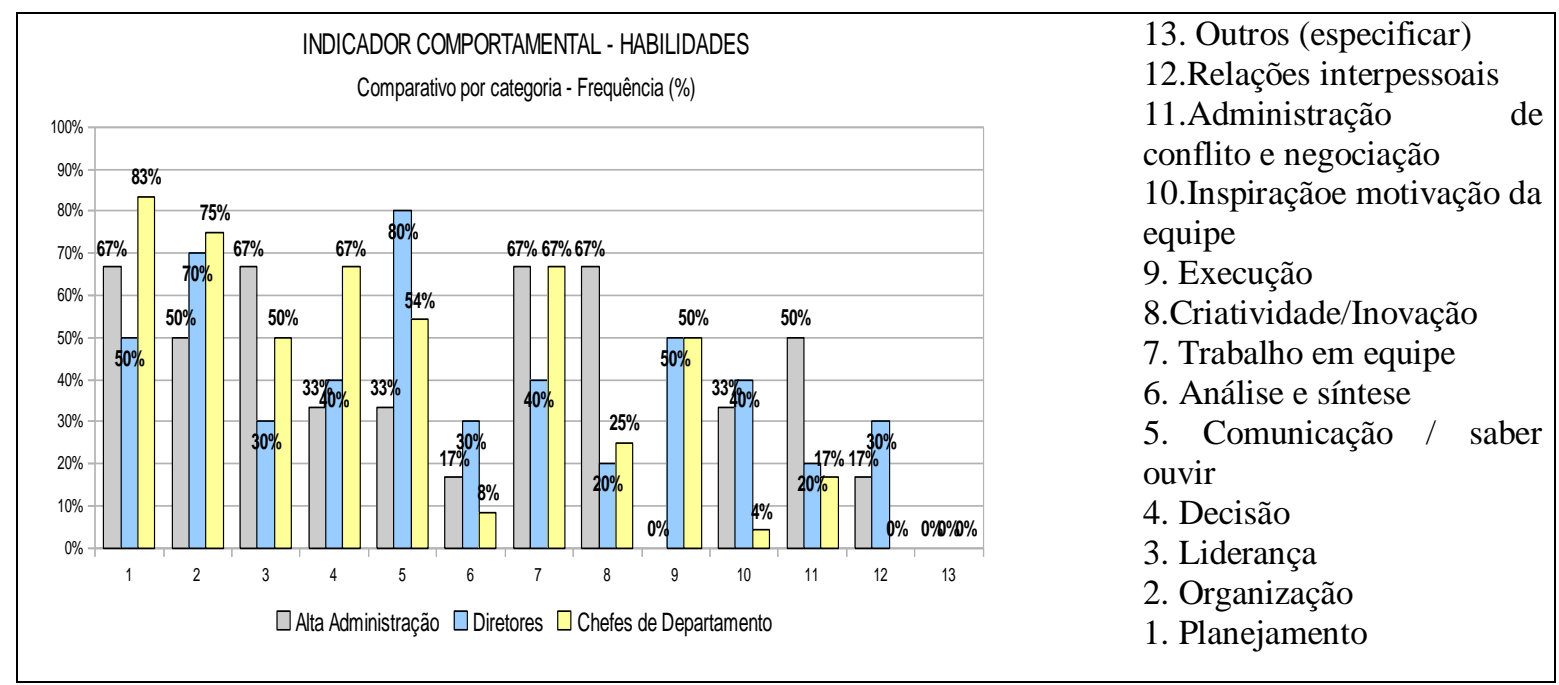

Fonte: Pesquisa das autoras.

Ao avaliar o indicador comportamental (habilidades) nas categorias (gráfico 4), os gestores da alta administração não atribuem nenhuma nota ao indicador 9 (execução). Bossidy e Charam (2004) chamam a atenção para os líderes sobre a importância da execução. De acordo com os referidos autores, o líder que ficar preso somente no pensar caminha para o fracasso. A execução é parte integrante da estratégia. Nesse sentido, tanto os diretores quanto os chefes de departamento reconheceram esta importância e atribuíram a este item, portanto, uma frequência de $50 \%$.

\subsection{Indicador Comportamental - Atitudes}

As atitudes consideradas mais importantes para os gestores da UERN estão apresentadas no gráfico 5. Estas atitudes significam a capacidade de agir e de fazer. De acordo com Durand (1998 apud EBOLI, 2004), atitudes referem-se à postura e ao modo como as pessoas agem e procedem em relação a fatos, objetos e outras pessoas de seu ambiente. É o querer fazer.

Quando questionados sobre as atitudes, os gestores da UERN deram destaque à atitude ética no exercício profissional (90\%), ou seja, respeito absoluto pelo outro, honestidade e justiça nas decisões e coerência entre o discurso e a prática. 
Gráfico 5 - Resultado indicador comportamental (atitude) - frequência (\%).

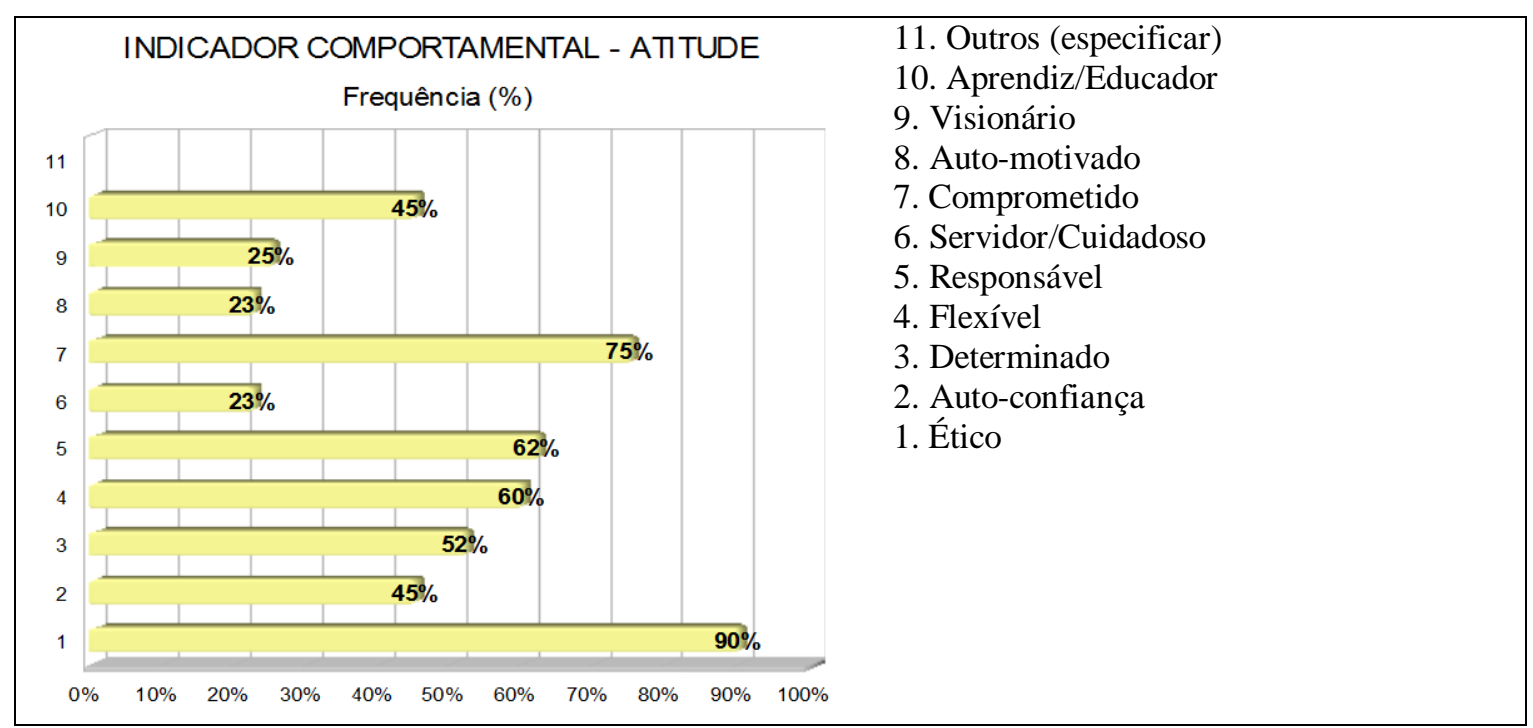

Fonte: Pesquisa das autoras.

Em segundo lugar, com $75 \%$ das escolhas, o mais importante para os gestores é ser comprometido. O comprometimento passa pela aceitação. Conforme Senge (2006), além de um estado de participação, envolve um sentimento de total responsabilidade na transformação da visão em realidade. Bastos (1996) define como um vínculo mais profundo do indivíduo com o seu trabalho. Já para Davenport (2001) provém de um elo emocional ou intelectual que une o individuo a organização, desejo intenso de participar e concordância tácita em rejeitar outras opções de investimento.

Com $62 \%$ das escolhas, os gestores consideram, em terceiro lugar, a variável do ser responsável.

Fazendo o comparativo dos dados nas categorias de gestores, observa-se, no gráfico 6 , que os indicadores que receberam menor pontuação pela alta administração foram: o indicador 4 (flexível) e o 8 (auto-motivado). Este último significa ter entusiasmo, evidenciado na postura corajosa de superação dos desafios do dia a dia, fator este essencial em um gestor. Nesse sentido, é fundamental que o gestor acredite em si mesmo e supere obstáculos.

Gráfico 6 - indicador comportamental (atitude) - Comparativo por categoria - frequência (\%). 


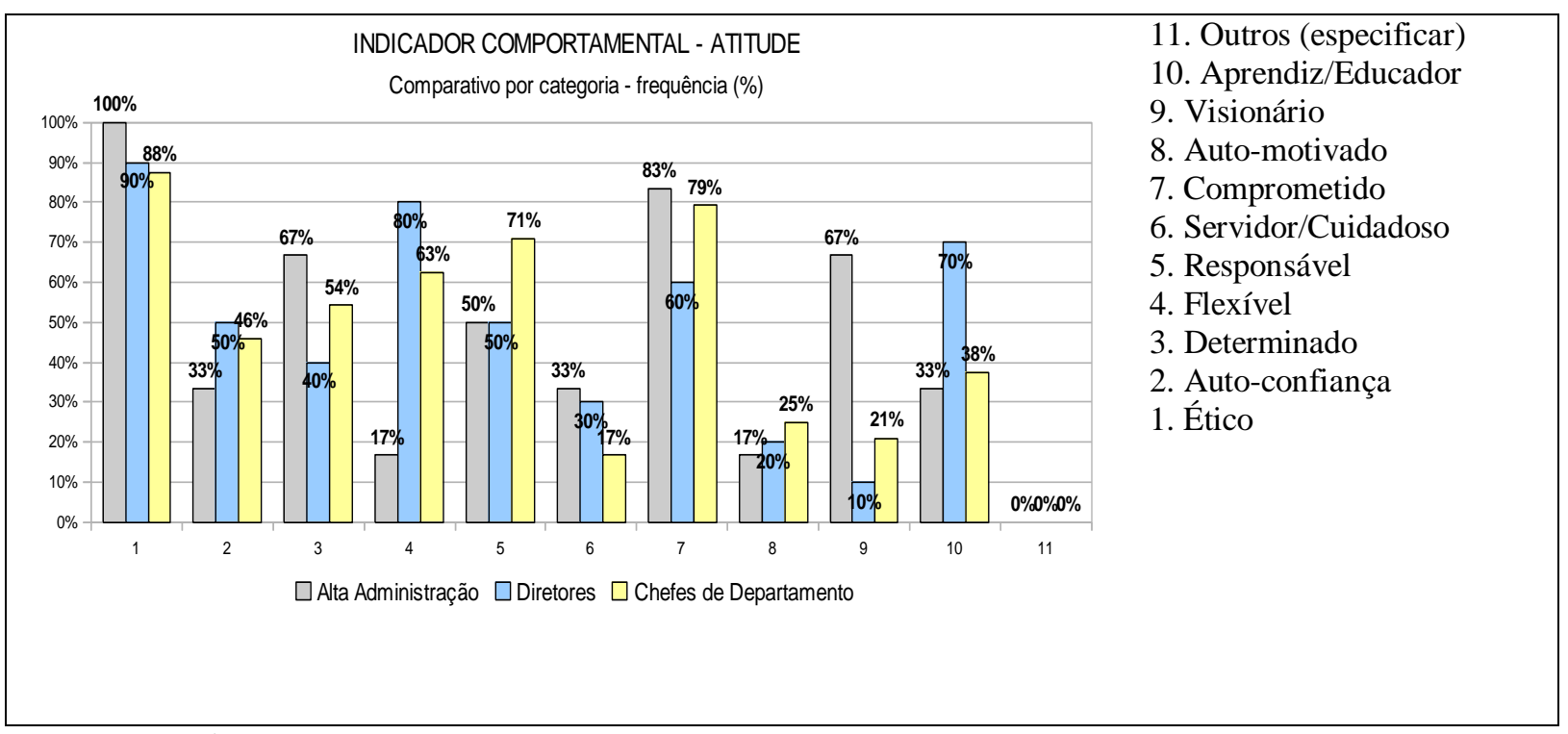

Fonte: Pesquisa das autoras.

Quanto ao indicador menos escolhido pelos diretores foi o 9, visionário, referindo-se a antevisão de cenários (sonhos), para onde deseja levar a organização e a equipe e, também, a disposição para compartilhar estes sonhos com seu grupo de trabalho, constatando assim que falta nos diretores uma valorização na visão compartilhada.

\subsection{Desenvolvimento Profissional}

A seguir serão apresentados os resultados obtidos por meio das perguntas abertas. Inicialmente, questionou-se aos gestores sobre a percepção deles a respeito das competências que julgavam possuir e das que deveriam ter para o exercício do trabalho como gestor.

Com base nesses questionamentos, foi possível observar, na análise das falas referentes a esta questão, que a totalidade dos gestores considera ter competências para atuar no cargo, embora tenha sido observada certa dificuldade em definir o que vem a ser competência.

Após agrupar as falas dos gestores, em torno daquilo que foi possível ser considerado como competência, identificou-se as mais recorrentes. Com isso, entre os chefes de departamento a capacidade de trabalhar em grupo foi considerada a primeira competência mais importante, sendo constatada nas falas dos chefes (C02, C07, C08, C14, C15 e C19) e evidenciada na fala do chefe C04 que declara o seguinte: "Tenho capacidade de aglutinação, 
administrar diferenças, liderança, disponibilidade para aprender e crescer”.

O segundo indicador mais citado pelos chefes de departamento foi a organização. Tal indicador foi verificado nas falas dos chefes C01, C12 e C15. O chefe de departamento C14 é quem melhor define esta ideia:

Depois de quase dois anos de gestão percebo que essa idéia, a de gestão, não me era familiar no momento em que fui eleito. No decorrer desse período é que se passou a compreender que o exercício da chefia de um departamento exige algumas competências como capacidade de organização, saber trabalhar em grupo, liderança, características que acredito já possuía (C14).

A responsabilidade e o compromisso também foram destacados como relevantes dentro do quadro de competência para ser um gestor na UERN. Os chefes C01 e C22 corroboram com esta ideia evidenciada na fala da gestora C13 ao afirmar: "Tenho compromisso e responsabilidade, e acima de tudo considero-me uma eterna aprendiz".

O comportamento ético também foi destacado nas falas dos chefes, o que confirma o grande índice das escolhas no indicador comportamental atitudes, comprovando o respeito absoluto pelo outro. Isso pode ser observado nas falas dos chefes C05 e C22, bem como no seguinte depoimento: "Tenho: habilidade para identificar processos de trabalho e gerenciar rotinas; postura ética de responsabilidade e compromisso com o trabalho (C01)".

O planejamento e a execução foram a quinta competência mais importante. Este indicador nos lembra a importância do líder em planejar e fazer acontecer. Isto pode ser confirmado na fala do chefe C02 e observado no depoimento do chefe C08: "Planejar e executar estratégias que viabilizem o desenvolvimento da dinâmica acadêmica conforme o interesse e compromisso coletivos. Deveria ter especialização na área (mais conhecimentos teóricos)".

O que se pode observar, quando se questionou aos chefes de departamento da IES, no tocante as competências que eles deveriam ter para o exercício da gestão, é a necessidade de um maior conhecimento dos aspectos legais que determinam tal exercício na UERN, isto é verificado nas seguintes falas:

\footnotetext{
Avalio que necessito aprofundar conhecimentos acerca dos aspectos legais e normativos que permeiam os encaminhamentos inerentes ao cargo (C02);

Acredito que posso adquirir maior conhecimento sobre as rotinas administrativas do meu departamento (C03);

Competência que deveria ter: maior conhecimento sobre legislação/processo/atores da instituição (C19).
} 
No que se refere às competências que deveriam possuir para o exercício de seu trabalho como gestor, os diretores de faculdades destacaram, em primeiro lugar, a ética no serviço. Este resultado pode ser observado nas falas dos seguintes diretores:

Compromisso com a função/cargo ocupado ética no serviço. Busca de soluções compartilhadas (D02);

A ética permite visualizar melhor todo processo administrativo; sem ética tudo mais e vazio, mero exercício de poder (D08).

Os diretores também destacaram outras competências, embora com menor frequência, dentre elas: responsabilidade e compromisso, capacidade de trabalhar em grupo, planejamento e execução e, por fim, liderança. Tais competências, também, já foram observadas nos depoimentos dos chefes de departamento.

Ao serem questionados a respeito do que necessitavam aprender para o exercício de seu cargo, os diretores de cursos afirmaram que precisavam possuir um maior conhecimento da área financeira. Essa necessidade foi constatada no depoimento deste diretor: "Acho que me falta uma maior aproximação teórica sobre gestão financeira e execução orçamentária de órgãos públicos (D07)”.

Os gestores da alta administração afirmaram que as competências mais relevantes para o exercício da gestão são: a responsabilidade e o compromisso, a administração financeira e a administração de conflitos. Quando questionados sobre o que precisavam aprender, estes gestores declararam ter dificuldades na tomada de decisão, nas rotinas administrativas da instituição, e que necessitam de um maior conhecimento do comportamento humano.

Quando foi perguntado aos chefes de departamentos se a UERN trabalha a gestão de competências como uma política institucional, aqui entendida como os princípios gerais que orientam as ações da instituição, $75 \%$ dos chefes de departamento afirmaram não visualizar nenhuma política de gestão de competência na instituição. Este resultado pode ser verificado nas falas dos chefes C01, C 02, C03, C10, C11, C12, C14, C15, C16, C17, C19, C20 e C23. Os depoimentos a seguir confirmam o resultado em questão:

Não. Pois não há cursos específicos para os gestores nem treinamento. As escolhas dos gestores se dá mais por questão políticas que técnicas (C04);

Não. Pois não vejo uma "integração" ou ações que visem à melhoria da qualidade de vida, no seu dia a dia dos nossos funcionários (C07);

Ainda não. As competências elencadas da instituição no nível formal, em grande parte é do desconhecimento de muitos agentes (C21). 
O fato da gestão de competência não se constituir uma política institucional na percepção dos gestores, se deve à análise das falas dos chefes de departamentos desta IES aos seguintes aspectos: falta de um programa, falta de um plano de capacitação e a distribuição de cargos sob condições políticas eleitorais. Isso pode ser observado nas seguintes falas:

Não. Pois deveria implantar um programa de desenvolvimento de competências e modernização das diversas unidades administrativas (C01);

Não. Passamos em concursos para lecionar, o que limita a nossa atuação enquanto gestores em virtude de não termos um know how necessário para a realização de tal atividade e a UERN não disponibiliza nenhum tipo de política institucional que nos auxilie na realização de tal tarefa $(\mathrm{C} 14)$;

Não, a UERN aplica um modelo pessoal e político de gestão (C20).

Um total de $21 \%$ dos chefes de departamento afirma que a IES apresenta uma política de gestão por competência e 4\% optaram em não responder esta pergunta no questionário. Embora os chefes de departamento confirmem que a gestão de competência faz parte da política da instituição, em seus depoimentos estes afirmaram que ainda existe muito a ser feito. Isto pode ser confirmado nos depoimentos a seguir:

Sim. Há uma preocupação com a formação de pessoal por setores. Claro, que precisa ser ampliada, mas para inicio, esta política é positiva (C08);

Acho que a UERN inicia esse trabalho de gerar competências. Mas ainda há muito a ser feito (C13);

Sim. E deve intensificar mais. O cumprimento do PDI, PPI e PPC justificam minha resposta $(\mathrm{C} 18)$.

Quanto aos diretores de faculdades, quando questionados sobre a gestão de competências dentro da UERN, 70\% assinalaram que ainda não se constitui uma política institucional, conforme depoimentos abaixo:

Não devido as condições históricas, como ocorreu a composição dos quadros funcionais (D03);

Não. A UERN coloca em áreas totalmente diferentes da formação de seus gestores (D04);

Não predomina os aspectos políticos em detrimentos dos aspectos acadêmicos (méritos, compromisso, ética, coerência, etc.) (D05).

Cerca de $20 \%$ dos diretores de faculdades demonstraram não ter certeza sobre este aspecto e $10 \%$ afirmaram que a gestão de competência faz parte da política institucional da UERN, como pode se observar na fala do diretor: "Sim, Os gestores observam atentamente os documentos oficiais que regem a instituição (estatuto, regimento, PDI) verão as competências 
especificas ao cargo que assumem, e agir (D01)".

Para $17 \%$ dos gestores que atuam na alta administração, a IES não trabalha a gestão de competência como política institucional, pois, para que isto ocorra, às estratégias devem fazer parte da gestão. O depoimento abaixo ressalta a consideração apresentada:

Não. Trabalham de forma pontual, pois a medida que enaltece o mérito, a capacitação acadêmica, a progressão por titulação, ainda não conseguiu instituir uma política, onde a avaliação, as competências e o desempenho sejam definidores de estratégias de gestão (A03).

Segundo $83 \%$ dos gestores que atuam na alta administração, quando questionados sobre este aspecto, a gestão de competência faz parte da política institucional, conforme pode ser verificado nos seguintes depoimentos: A UERN aplica atenção e recursos na política de capacitação, tanto docente quanto
técnico administrativo. Necessita realmente eleger como prioridade gestão de
competências. Ainda tem muito a melhorar (A01);
O plano de desenvolvimento institucional PDI, foi aprovado faltando apenas que na
prática seja executado (A05).

Alguns chefes de departamento, diretores e gestores da alta administração reconhecem a gestão de competências como parte da política institucional, e se referem aos seguintes documentos: PDI, Estatuto e Regimento. Estes depoimentos revelam uma visão limitada sobre a compreensão do que vem a ser a gestão de competência, uma vez que os documentos citados não definem as competências necessárias a cada cargo, e sim as normas que regem a IES. A própria Pró-reitoria de Recursos Humanos e alguns participantes do estudo informaram não existir na instituição nenhum documento que trace as competências dos gestores da IES.

Ao serem perguntados sobre as aprendizagens que foram necessárias para ocupar a função, os chefes de departamento afirmaram que tiveram que aprender a legislação da IES, os processos administrativos, a administrarem conflitos e a serem éticos e flexíveis. Quando questionados sobre como este aprendizado ocorreu, afirmaram que foi por iniciativa própria, em sua grande maioria, com as experiências vivenciadas no dia a dia, estudando os documentos da instituição, observando os funcionários mais experientes, e outros afirmaram trazer experiências de cargos anteriores. Isto pode ser observado nos depoimentos abaixo: 
Ser um gestor administrativo. Esse aprendizado está ocorrendo no dia a dia com a prática e com os erros (C09);

Processo de funcionamento do departamento (procedimentos, leis). Aprendizado ocorreu no contato com funcionários mais experientes e através da leitura de documentos institucionais (C19);

Os processos administrativos relativos a minha função, que foram adquiridos com a experiência, mas que seriam melhor aproveitados se tivesse ocorrido um treinamento prévio (C23).

No que diz respeito ao processo de aprendizagem na instituição, os diretores de faculdades destacaram que tiveram que aprender a dizer não diante de algumas situações, a conquistarem o respeito de seus pares, a planejar e a negociar. Uma afirmativa que chamou atenção foi a de um gestor, o qual assinalou o fato de que a convivência diária com os conflitos e descaso de alguns com o serviço público, o fez aprender a negociar, planejar e buscar a participação efetiva junto à instituição.

Para os diretores, o processo de aprendizagem ocorreu no dia a dia, e por esforço próprio. Outros gestores trouxeram experiências de outras empresas nas quais trabalharam. Nesse sentido, observando os depoimentos destes diretores confirma-se a fala dos chefes de departamento:

Aprendi com a experiência anterior em entidade privada, onde exercia cargo de gestor. O aprendizado deu-se no esforço próprio e a experiência do cargo acima citado (D09);

Aprender a dizer não diante de uma situação administrativa que envolvia a saúde, o financeiro, ser mais cuidadosa; como administrar conflitos interpessoais. A partir dos conhecimentos teóricos, bem como da experiência de vida (D10).

Além das experiências adquiridas, os gestores da alta administração declararam que tiveram que aprender sobre planejamento, legislação, políticas públicas, a trabalharem sob pressão e a lidarem com pessoas. Esta aprendizagem ocorreu por meio de leituras, reuniões e no dia a dia. Isto é ressaltado nos seguintes depoimentos:

Tive que aprender um pouco de planejamento de legislação interna e da administração a respeito dos gastos públicos. E também sobre as políticas públicas para o ensino superior, ciência e tecnologia. Ocorreu por auto-aprendizado, em reuniões de equipe e em encontro do MEC, CAPES, ABRUEM (A02);

Aprendi a trabalhar no limite, ou melhor, sob pressão; Aprendi que a ética e a justiça não satisfaz a todos; Aprendi que lidar com pessoas, leva a necessidade de aprendizado constante. O aprendizado foi cotidiano e doloroso (A03);

Aprendemos através da prática do dia a dia no entender da instituição com a ajuda do conhecimento teórico através da leitura e do curso de gestão universitária (A05).

Realizou-se o seguinte questionamento aos chefes de departamento: se eles tivessem 
que escolher alguém para substituí-lo, quais competências exigiriam para a sua função? Estes alegaram que o seu substituto deve ser comprometido e responsável, gostar de trabalho em equipe, possuir liderança, ter conhecimento das rotinas da instituição, postura ética e saber planejar e organizar.

Em relação às competências que seus substitutos devem possuir, os diretores ressaltaram que estes devem ser pessoas éticas e comprometidas com a instituição, ter conhecimento das tarefas desempenhadas, saber planejar, definindo as prioridades e ter capacidade para o diálogo e a criatividade.

Já os gestores da alta administração definem como importante para os substitutos as seguintes competências: ter postura ética, ser comprometido e responsável com a IES, ter conhecimento das tarefas, estarem dispostos a aprender, capacidade de decisão e, acima de tudo, humildade para suportar situações. Isto é expresso na fala deste gestor: "Ter conhecimento sobre a UERN. Ter habilidade para suportar situações. Tomar atitudes nas horas precisas. Possuir e exercitar ética (A01)".

Portanto, as respostas mais citadas pelos gestores apontaram a importância da postura ética, do conhecimento institucional e compromisso com a instituição e com a função desempenhada. Tais resultados confirmam os indicadores cognitivos (conhecimentos) e os indicadores comportamentais (habilidades e atitudes), indicados pelos gestores.

Ao solicitar aos gestores (chefes de departamento, diretores e alta administração) que dessem sugestões para que a UERN pudesse desenvolver políticas sistematizadas de gestão de competências, um gestor disse que a instituição deveria: "Começar de fato a gerenciar na prática e sair apenas dos infindáveis relatórios; avaliações, planos, PDI, etc. (D09)".

Outras sugestões foram sinalizadas, como: “A IES deve oferecer cursos de capacitação para formação de gestores, que fosse construído um fórum de discussão, que existisse um banco de dados entre as pró-reitorias para que ocorra uma maior interligação e o processo de comunicação e documentos (memorando/ofícios) flua mais rápido e que a IES procure garantir a ocupação de cargos de diretoria administrativa, pró-reitoria e cargos centrais, mediante consulta pública”. Atualmente, estes cargos são de confiança e indicados pelo reitor.

Em suma, percebe claramente que os gestores pesquisados desconhecem o sentido real do termo competência, pois algumas das sugestões apresentadas apontam mais para problemas vivenciados por falta de planejamento do que para uma real política de gestão de competências. 


\section{CONSIDERAÇÕES FINAIS}

Esta pesquisa analisou a percepção dos gestores sobre as competências ideais necessárias ao exercício da gestão. Com isso, foi possível perceber que os gestores sinalizaram comprometimento com a função que exercem e com a IES, defendendo assim a importância do planejamento e do agir com ética nas ações que desenvolvem.

Os objetivos deste estudo foram atingidos, uma vez que se buscou analisar esta percepção. Os objetivos específicos propostos também foram atingidos. Quando se verificou como os gestores percebem a gestão de competências como uma política da instituição, alguns gestores afirmaram que não passavam de reuniões enfadonhas e não se conseguia que os projetos saíssem do papel. Enquanto que outros gestores acreditam que faz parte da política da IES, embora defendam que tem muita coisa a melhorar.

Ao mapear as habilidades que os gestores consideram mais importante, o planejamento ganhou destaque, confirmando a importância que os gestores deram ao planejamento estratégico e operacional no indicador cognitivo - conhecimento.

Em relação ao indicador comportamental (atitudes), observou-se que os gestores destacam a ética, o comprometimento, o ser flexível e a determinação como atitudes essenciais para um gestor.

A Instituição, a partir da percepção dos gestores, parece necessitar de um processo de sensibilização, a fim de sistematizar programas e acompanhamentos que contribuam para o desenvolvimento das competências gerenciais em seus gestores, como forma de melhor subsidiá-los nas tomadas de decisões.

Assim sendo, foi evidenciada a ausência de programas contínuos de acompanhamento ao trabalho dos gestores, necessidade essa sinalizada por alguns dos participantes da pesquisa. Estes reconhecem que o processo da aprendizagem ainda vem acontecendo, na maioria das vezes, pelos ensaios e erros no dia a dia. Porém, esse procedimento termina sendo bastante oneroso e ineficiente para qualquer instituição, ainda mais quando se trata de uma IES pública, cujo papel principal é a produção e divulgação de conhecimentos. E esta tem que dar um retorno à sociedade.

A limitação deste estudo está centrada na questão de que os resultados apontados, por meio do estudo de campo, apesar de sua contribuição, não visualiza a generalização dos mesmos, uma vez que a pesquisa foi aplicada apenas no Câmpus Central da UERN na cidade Revista LABOR $\quad$ nºr $^{0}$ v.1, 2016

ISSN: 19835000 
de Mossoró-RN.

Dessa forma, este estudo oferece abertura para novas pesquisas e sugestões para outras pesquisas desta temática, aplicando o questionário a outros atores do processo, tais como, os diretores que atuam nos Campi Avançados, os quais venham contribuir para o avanço científico e melhoria das organizações quanto às competências gerenciais e o processo de aprendizagem, pois o grande diferencial hoje nas organizações são as pessoas. Somente estas são capazes de transformar e superar os desafios impostos pelo ambiente organizacional.

Frente ao exposto, sugere-se que sejam realizados estudos e planejamentos, nos quais as competências citadas como necessárias para os gestores, sejam examinadas por pessoas que elaboram programas de capacitação gerencial, com o objetivo de defini-las tecnicamente, a fim de serem utilizadas na elaboração de treinamento e desenvolvimento para os professores que assumem cargos de gestão nesta IES.

\section{REFERÊNCIAS}

ALMEIDA, E. P. de. A Universidade como Núcleo de Inteligência Estratégica. In: MEYER, V. Jr.; MURPHY, J. P. (Org.) Dinossauros, gazelas \& tigres. Novas abordagens da administração universitária. Um diálogo Brasil e EUA. Florianópolis: Insular, 2000.

ANTONELlO, C. S. A metamorfose da aprendizagem organizacional: uma revisão crítica. In R. Ruas, C. S. Antonello, \& L. H. Boff (Orgs.), Aprendizagem organizacional e competências (pp.12-33). Porto Alegre: Artmed, 2005.

BASTOS, A.V. Comprometimento no Trabalho: alguns fundamentos téoricos. Salvador: Universidade Federal da Bahia, 1996.

BRAGA, Luciano J.; BRITO, Lydia M. P. Perfil ideal de competência profissional de gestores da área de saúde. EnGPR - ANPAD. Anais... 2009. CD-ROM.

BRANDÃO, H.; GUIMARÃES, T. Gestão de Competências e Gestão de Desempenho: tecnologias distintas ou instrumentos de um mesmo construto. In Encontro Nacional dos Programas de Pós-Graduação em Administração. Conferência, Foz do Iguaçu, 1999. 
BITENCOURT, Claudia Cristina. Gestão de competências e aprendizagem nas Organizações gerenciais. São Leopoldo-RS: Editora Unisinos, 2005.

BITENCOURT, Claudia Cristina. A gestão de competências gerenciais: a contribuição da aprendizagem organizacional. Porto Alegre, 2001.

BRITO, Lydia M. P. Gestão de Competências, Gestão do Conhecimento e Organizações de Aprendizagem: instrumentos de apropriação pelo capital do saber do trabalhador. Fortaleza: Imprensa Universitária, 2005.

BOENTE, Alfredo; BRAGA, Gláucia. Metodologia científica contemporânea: para universitários e pesquisadores. Rio de Janeiro: Brasport, 2004.

BOFF, L. Virtudes para um outro mundo possível: hospitalidade: direito e dever de todos. Petrópolis: Vozes, 2005. v. 1.

BOSSIDY, Larry; CHARAM, Ram. Execução: a disciplina para atingir resultados. Tradução de Elaine Pepe. Rio de Janeiro: Elsevier, 2004.

CAMPOS, Daniela Cristina da Silveira. Competências gerenciais dos pró-reitores em uma instituição de ensino superior: um estudo de caso na Universidade Federal de ViçosaMG. Viçosa- MG. 2007 143f. Dissertação (Mestrado) - Universidade Federal de Viçosa-MG. Viçosa- MG, 2007.

DAVENPORT, Thomas O. Capital humano: o que é e por que as pessoas investem nele. Tradução de Rosa S. Krausz. São Paulo: Nobel, 2001.

DUTRA, Joel Souza. Gestão de pessoas: modelo, processos, tendências e perspectivas. São Paulo: Atlas, 2002.

EBOLI, M. Educação corporativa no Brasil: mitos e verdades. São Paulo: Editora Gente, 2004. 
FLANNERY, Thomas P. e outros. Pessoas, Desempenho e Salários. São Paulo: Futura,1997.

FLEURY, Maria Tereza Leme; OLIVEIRA JÚNIOR, Moacir de Miranda. Gestão estratégica do conhecimento: integrando aprendizagem, conhecimento e competências. São Paulo: Atlas, 2001.

GRAMIGNA, Maria Rita. Modelo de competências e gestão dos talentos. 2 ed. São Paulo: Pearson Prentice Hall, 2007.

GIL, Antonio Carlos. Métodos e técnicas de pesquisa social. São Paulo: Atlas, 2007.

LE BOTERF, Guy. Desenvolvendo a competência dos profissionais. Porto Alegre: Artmed, 2003.

LIMA, Manolita Correia. Monografia: a engenharia da produção acadêmica. São Paulo: Saraiva, 2004.

RAMOS, Alberto Guerreiro. Modelo de Homem e Teoria Administrativa. Caderno de Ciências Sociais Aplicadas. Mestrado de Administração. PUC/PR, 2001.

RESENDE, Enio. O livro das competências: desenvolvimento das competências: a melhor auto-ajuda para as pessoas, organizações e sociedade. Rio de Janeiro: Quallitymark, 2000.

RUAS, Roberto et al. Aprendizagem organizacional e competências. Porto Alegre: Bookman, 2003.

RUAS, R.; ANTONELLO, C.; BOFF, L. Os novos horizontes da gestão: aprendizagem organizacional e competências. Porto Alegre: Bookman, 2005.

RUAS, R.; ANTONELlO, Claudia Simone. A metamorfose da aprendizagem: uma revisão crítica. In: RUAS, Roberto et al.(Org). Os novos horizontes da gestão: aprendizagem organizacional e competências. Porto Alegre: Bookman, 2005. p. 12-33. 
SENGE, P. A quinta disciplina: arte, teoria e pratica da organização de aprendizagem. Tradução Regina Amarante. São Paulo: Best Seller, 2006.

SVEIBY, Karl Erick. A nova riqueza da organizações. Tradução de Luiz Euclydes Trindade Frazão Filho. Rio de Janeiro: Câmpus, 1998.

UNIVERSIDADE DO ESTADO DO RIO GRANDE DO NORTE. Estatuto da UERN. Mossoró, RN, 1997. Disponível em: <http://www.uern.br>. Acesso em: 15 jun. 2010.

UNIVERSIDADE DO ESTADO DO RIO GRANDE DO NORTE. Regimento geral da UERN. Mossoró,RN, 2002. Disponível em: <http://www.uern.br>. Acesso em: 15 jun. 2010.

UNIVERSIDADE DO ESTADO DO RIO GRANDE DO NORTE. Aprova normas para concessão do Regime de Trabalho de Tempo Integral com Dedicação Exclusiva-DE e revoga a Resolução n 29/2008-CONSEPE. Resolução n. 7/2009 - CONSEPE. Mossoró,RN, 2009.

ZARIFFIAN, Philippe. Objetivo competência: por uma nova lógica. Tradução de Maria Helena C. V. Trylinski. São Paulo: Atlas, 2008.

\footnotetext{
${ }^{1}$ Doutoranda em Administração pela Pontifícia Universidade Católica do Paraná - (PUCPR), Mestre em administração pela Universidade Potiguar (UNP) e Professora do Curso de Administração da Universidade do Estado do Rio Grande do Norte (UERN). E-mail: andreakaliany@ yahoo.com.br

${ }^{2}$ Mestre em Sociologia e Doutora em Educação pela Universidade Federal do Ceará. Professora do Mestrado em Administração da Universidade Potiguar (UNP). E-mail: lydiampbrito@yahoo.com.br
}

RECEBIDO EM: Abril de 2016

APROVADO EM: Junho de 2016 